\title{
Pretreatment Neutrophil-to-Lymphocyte Ratio Predicts Survival After TAS-102 Treatment of Patients With Metastatic Colorectal Cancer
}

\author{
AKIHISA MATSUDA ${ }^{1,2}$, TAKESHI YAMADA ${ }^{2}$, SATOSHI MATSUMOTO $^{1}$, \\ NOBUYUKI SAKURAZAWA ${ }^{1}$, YOUICHI KAWANO ${ }^{1}$, ERIKO SHINOZUKA $^{1}$, KUMIKO SEKIGUCHI $^{1}$, \\ HIDEYUKI SUZUKI ${ }^{1}$ and HIROSHI YOSHIDA ${ }^{2}$ \\ ${ }^{1}$ Department of Surgery, Nippon Medical School Chiba Hokusoh Hospital, Chiba, Japan; \\ ${ }^{2}$ Department of Gastrointestinal and Hepato-Biliary-Pancreatic Surgery, Nippon Medical School, Tokyo, Japan
}

\begin{abstract}
Background/Aim: TAS-102 is recommended as salvage-line therapy for metastatic colorectal cancer (mCRC), but practical predictors for its efficacy are lacking. Patients and Methods: In a single-institutional retrospective study of 33 patients treated with TAS-102, we investigated the predictive value of the pretreatment neutrophil-tolymphocyte (NLR), platelet-to-lymphocyte (PLR), and lymphocyte-monocyte (LMR) ratios for progression-free $(P F S)$ and overall (OS) survival. Predictive ability using cutoffs of the median value (3.14) and 5 for NLR were compared. Results: In univariate analysis, Eastern Cooperative Oncology Group performance score, NLR, and PLR were negatively significantly associated with PFS and $O S$. The number of treatment lines was negatively associated with PFS. The NLR cut-off of 5 was superior to the median value. Multivariate analyses showed a significant prognostic impact for NLR at cut-off 5 (hazard ratio $(H R)=6.26, p=0.02$ for PFS; HR=6.97, $p=0.07$ for OS). Conclusion: The pretreatment NLR is a prognostic biomarker for patients with $m C R C$ who receive TAS-102 treatment.
\end{abstract}

TAS-102 is an oral combination of trifluridine (FTD, a thymidine-based nucleoside analogue) and tipiracil hydrochloride (a thymidine phosphorylase inhibitor) at a molar ratio of 1:0.5. FTD is incorporated into DNA after phosphorylation by thymidine kinase-1 (TK1), causing DNA

Correspondence to: Akihisa Matsuda, MD, Department of Gastrointestinal and Hepato-Biliary-Pancreatic Surgery, Nippon Medical School, 1-1-5 Sendagi, Bunkyo-ku, Tokyo 113-8603, Japan. Tel: +81 338222131, Fax: +81 356850989, e-mail: amatsu@nms.ac.jp

Key Words: Metastatic colorectal cancer, TAS-102, predictive marker, survival. dysfunction, whereas tipiracil is a pharmacokinetic modulator that maintains the blood concentration of FTD by inhibiting the enzyme responsible for its degradation, thymidine phosphorylase $(1,2)$.

The clinical benefits of TAS-102, namely significant improvements of overall (OS) and progression-free (PFS) survival, in patients with chemotherapy-refractory metastatic colorectal cancer (mCRC) were initially shown in a randomized, placebo-controlled, phase II trial in Japan (J003 study), and reproduced in international phase III trials, RECOURE study and TERRA study (3-5). TAS-102 is, therefore, indicated as a standard treatment option for patients with $\mathrm{mCRC}$ treated with fluoropyrimidine-, oxaliplatin- or irinotecan-based chemotherapies and targeted therapies as a third-line or subsequent therapy.

A global focus related to TAS-102 therapy is identifying predictors of its efficacy. Although several preliminary studies have investigated predictive biomarkers (6-9), no objective biomarker has yet been identified. Relationships between cancer treatment outcomes and inflammationbased indicators, including the neutrophil-to-lymphocyte ratio (NLR), platelet-to-lymphocyte ratio (PLR), lymphocyte-to-monocyte ratio (LMR), C-reactive protein (CRP), and modified Glasgow prognostic score (mGPS), have been widely studied. Among these, the NLR is a representative index. An elevated NLR reflects greater systemic inflammation, which can induce cancer progression via production of pro-inflammatory and angiogenic cytokines, and is associated with reduced tumour-specific immunity, including a reduced number of tumour-infiltrating lymphocytes in the tumour microenvironment $(10,11)$. It is reportedly associated with poor survival in patients with resectable CRC and mCRC $(12,13)$. This study investigated the potential of pretreatment inflammation-based scores for patients with $\mathrm{mCRC}$ to predict TAS-102 efficacy. 


\section{Patients and Methods}

This was a retrospective single-institutional study conducted at the Department of Surgery of Nippon Medical School Chiba Hokusoh Hospital from August 2014 to March 2018, and included 33 patients with mCRC who were treated with TAS-102 after standard therapies. All patients had presented with histologically confirmed colorectal adenocarcinoma.

Patients' baseline characteristics were collected from medical records. TAS- 102 was given orally at $35 \mathrm{mg} / \mathrm{m}^{2}$ twice a day for 28 days (one course): Two-week cycles of 5 days of treatment and 2 days of rest, followed by 14 days of rest. This treatment cycle was repeated until disease progression or the physician's judgement to cease this regimen.

Adverse events (AEs) of grade 3 or more were evaluated using the Common Terminology Criteria for Adverse Events, version 4.03 (14). Tumour response was evaluated by one investigator using the Response Evaluation Criteria in Solid Tumours (RECIST), version 1.1 (15) in patients with measurable disease at baseline. White blood cell, neutrophil, lymphocyte, monocyte, and platelet counts were routinely measured at a central laboratory, and pre-TAS-102 treatment NLR, PLR, and LMR were calculated for each patient.

PFS was defined as the interval from the start of the TAS-102 treatment to either disease progression or death. OS was defined as the interval from the start of the TAS-102 treatment to death. Patients were censored at their last follow-up visit if they were free of disease progression or alive, for PFS and OS analyses, respectively. Median PFS and OS were calculated with the KaplanMeier method. Differences between two patient groups were evaluated using the log-rank test. This study was conducted in accordance with the Declaration of Helsinki and the study protocol was approved by the Ethics Committee of Nippon Medical School Chiba Hokusoh Hospital (Chiba, Japan) (approval no. 748).

All statistical analyses were performed using R, version 3.1.0 (R Foundation for Statistical Computing, Vienna, Austria). Continuous variables are expressed as the median and range, and compared using two-tailed Student's $t$-tests and Mann-Whitney $U$-tests. Discrete variables were compared using chi-squared and Fisher's exact tests. Variables for which $p<0.1$ in univariate analysis were entered into multivariate Cox proportional hazard models. $p$-Values less than 0.05 were considered significant.

\section{Results}

Patient characteristics and treatment. In this study, 33 patients [median age $=69$ years; range $=48-90$ years; 20 men $(60.6 \%)]$ with mCRC were treated with TAS-102, including five $(15.2 \%)$ with Eastern Cooperative Oncology Group performance score (ECOG PS) $\geq 2,16(48.5 \%)$ with KRAS wild-type tumours, and 16 (48.5\%) who received TAS-102 as 4 th-line or higher treatment. The median number of TAS102 treatment courses was 4 (range $=1-18)$. Their characteristics are summarized in Table I.

Of the 33 patients, $22(66.7 \%)$ initially received full doses of TAS-102, and the other 11 patients started with lower doses at the physician's discretion (e.g. due to poor PS). Median values of NLR, PLR, and LMR were 3.14, 173.2, and 3.17 , respectively.
Predictive factors. Exploratory analyses were carried out to identify potential predictive factors for PFS and OS (Table II). Variables classified with age, sex, primary site, KRAS status, synchronous or metachronous metastasis, number of organs with metastases, and time from diagnosis to TAS-102 treatment showed no significant differences in PFS nor OS analyses. Patients with better ECOG PS ( 0 or 1 ) had significantly longer PFS and OS compared with those with PS of 2 or more (PFS=5.75 vs. 1.74 months: $p=0.007$; OS=12.45 vs. 2.69 months: $p<0.001$ ). Interestingly, patients treated with reduced initial TAS-102 doses had survival benefits similar to those treated with the standard dose. TAS102 in 3rd-line or earlier treatment led to significantly longer PFS than did 4th-line or later (5.98 vs. 2.97 months: $p=0.003$ ), but not OS.

Among haematological variables, a high NLR was associated with significantly shorter PFS and OS compared with a lower NLR at cut-offs of both 3.14 (PFS: $3.29 \mathrm{vs}$. 5.98 months: $p=0.031$; OS: $6.17 v s .12 .68$ months: $p=0.005$; Figure 1) and 5 (PFS: 1.64 vs. 6.05 months: $p<0.001$; OS: 4.30 vs. 12.71 months: $p<0.001$; Figure 2). The same pattern was observed for PLR (PFS: 3.23 vs. 6.28 months: $p=0.018$; OS: $7.98 v s .16 .33$ months: $p=0.003$ ). However, analyses of LMR and neutropenia within 1 month of TAS-102 treatment had no significant predictive impact. As these results indicated that the NLR cut-off of 5 had the best potential for predicting survival in univariate analyses, this value was used in further analyses.

Efficacy and safety according to NLR status (cut-off: 5). All patients had measurable disease at baseline, but one patient was not evaluated by computed tomography because of severe disease progression. Considering all cases, the overall response rate (ORR) was $3.0 \%$ and the disease-control rate (DCR) was $54.5 \%$. The ORR did not differ statistically according to NLR $(<5 v s . \geq 5: 0 \% v s .9 .1 \%)$. The DCR for those with NLR $\geq 5$ was worse than that with NLR $<5$, but not significantly so $(27.3 \%$ vs. $68.2 \%, p=0.061)$ (Table III).

In the safety profile (for AEs of grade 3 or more), no grade 4 nonhematological AEs occurred. Febrile neutropenia developed in four patients (12.1\%), three (13.6\%) with NLR $<5$ and one $(9.1 \%)$ with NLR $\geq 5$, but the difference did not reach statistical significance $(p>0.99)$. Neutropenia was less frequent in the group with NLR $\geq 5$ than that with NLR $<5$, but the difference did not reach statistical significance (18.2\% vs. 54.5\%, $p=0.067$ ) (Table III).

Multivariate analyses for survival at the NLR cut-off of 5 . In multivariate analysis (Cox proportional hazard model), two or more organs with metastases, fourth or more treatment line, NLR $\geq 5$ were associated with poorer PFS. ECOG PS and NLR were identified as independent prognostic factors in OS analysis (Table IV). 
Table I. Characteristics of the included patients $(n=33)$.

\begin{tabular}{|c|c|}
\hline Characteristic & Value \\
\hline \multicolumn{2}{|l|}{ Age, years } \\
\hline Median (range) & $69(48-90)$ \\
\hline \multicolumn{2}{|l|}{ Gender } \\
\hline Male & $20(66.7)$ \\
\hline Female & $13(39.4)$ \\
\hline \multicolumn{2}{|l|}{ ECOG PS, n (\%) } \\
\hline 0 & $21(63.6)$ \\
\hline 1 & $7(21.2)$ \\
\hline 2 & $3(9.1)$ \\
\hline 3 & $2(6.1)$ \\
\hline \multicolumn{2}{|l|}{ Primary site, $\mathrm{n}(\%)$} \\
\hline Right-sided & $8(24.2)$ \\
\hline Left-sided & $25(75.8)$ \\
\hline \multicolumn{2}{|l|}{ Metastasis, n (\%) } \\
\hline Synchronous/metachronous & $20(60.1)$ \\
\hline Metachronous & $13(39.4)$ \\
\hline \multicolumn{2}{|c|}{ Number of organs with metastasis, $\mathrm{n}(\%)$} \\
\hline 1 & $13(39.4)$ \\
\hline 2 & $14(42.4)$ \\
\hline 3 & $4(12.1)$ \\
\hline 4 & $2(6.1)$ \\
\hline \multicolumn{2}{|l|}{ KRAS status, n (\%) } \\
\hline Wild-type & $17(51.5)$ \\
\hline Mutant & $13(39.4)$ \\
\hline Unknown & $3(9.1)$ \\
\hline \multicolumn{2}{|c|}{ Treatment line of TAS-102, n (\%) } \\
\hline 2 & $4(12.1)$ \\
\hline 3 & $13(39.4)$ \\
\hline 4 & $7(21.2)$ \\
\hline 5 & $4(12.1)$ \\
\hline 6 & $3(9.1)$ \\
\hline 7 & $2(6.1)$ \\
\hline \multicolumn{2}{|c|}{ Time from diagnosis to TAS-102, months } \\
\hline Median (range) & $23.9(7.3-100.5)$ \\
\hline \multicolumn{2}{|c|}{ Combination with bevacizumab, n (\%) } \\
\hline Yes & $7(21.2)$ \\
\hline No & $26(78.8)$ \\
\hline \multicolumn{2}{|c|}{ Reduced dose of initial TAS-102, n (\%) } \\
\hline Yes & $11(33.3)$ \\
\hline No & $22(66.7)$ \\
\hline \multicolumn{2}{|c|}{ Number of TAS- 102 treatment courses } \\
\hline Median (range) & $4(1-18)$ \\
\hline \multicolumn{2}{|l|}{ Regorafenib treatment, $\mathrm{n}(\%)$} \\
\hline Yes & $6(18.1)$ \\
\hline No & $27(81.8)$ \\
\hline \multicolumn{2}{|c|}{ Further treatment after TAS-102, n (\%) } \\
\hline Yes & $7(21.2)$ \\
\hline No & $26(78.8)$ \\
\hline \multicolumn{2}{|l|}{ Pre TAS-102 treatment NLR } \\
\hline Median (range) & $3.14(1.08-41.50)$ \\
\hline \multicolumn{2}{|l|}{ Pre TAS-102 treatment PLR } \\
\hline Median (range) & $173.2(61.8-2437.4)$ \\
\hline \multicolumn{2}{|l|}{ Pre TAS-102 treatment LMR } \\
\hline Median (range) & $3.17(0.17-14.0)$ \\
\hline
\end{tabular}

ECOG PS: Eastern Corporative Oncology Group performance status; NLR: neutrophil-to-lymphocyte ratio; PLR: platelet-to-lymphocyte ratio; LMR: lymphocyte-to-monocyte ratio.

\section{Discussion}

This retrospective study indicated that among patients with refractory mCRC treated with TAS-102, pretreatment NLR and PLR were predictive of both PFS and OS in univariate analyses, and NLR was predictive of PFS and OS in multivariate analyses. This suggests that pretreatment blood inflammation-based scores (especially NLR) are prognostic/predictive biomarkers.

The NLR has been suggested as a prognostic factor in various solid tumours, including CRC (16-20). The NLR is a factor related to systemic inflammation, which is recognized as a 'hallmark of cancer'. The systemic inflammatory response plays important roles during all stages of tumorigenesis. It may lead to tumour initiation through genetic mutations, genomic instability, and epigenetic modifications. Inflammation activates tissue-repair responses that induce proliferation of premalignant cells and enhance their survival. It also contributes to angiogenesis, immunosuppression, inhibition of apoptosis, and DNA damage, ultimately promoting metastatic spread $(11,21)$. A high NLR represents a relatively elevated neutrophil count and depleted lymphocyte count. Neutrophils produce serum vascular endothelial growth factor (VEGF) and various matrix proteases (22). This tumour-promoting microenvironment facilitates tumour invasion and metastasis. Lymphocyte depletion attenuates tumour-specific immunity, including reducing the number of tumour-infiltrating lymphocytes $(10,11)$. Although distinct tumour-suppressive mechanisms are predominantly mediated by $\mathrm{CD} 4^{+}$or $\mathrm{CD} 8^{+}$ T-lymphocytes, regulatory $\mathrm{T}$-cells, a specific $\mathrm{CD}^{+}$cell population, have major functions in tumour-induced immunotolerance through suppression of $\mathrm{CD}^{+} \mathrm{T}$-lymphocytes. In contrast, $\mathrm{CD}^{+} \mathrm{T}$-lymphocyte counts, which are associated with humoral immunity and prevention of tumour rejection, are either normal or high during cancer progression $(23,24)$.

The pretreatment PLR also had some predictive potential for efficacy of TAS-102 treatment. Platelets are a critical source of cytokines, especially transforming growth factor- $\beta$ and VEGF, which can promote tumour growth by enhancing angiogenesis $(21,22,25)$.

Several studies have suggested that the NLR can predict response to systemic chemotherapy in patients with mCRC. However, most studies were designed in early-line treatment settings $(12,26-28)$. Chemotherapy drugs consistently utilized in each study were heterogeneous, including bevacizumab- $(12,26,29)$, oxaliplatin- (30), and cetuximabbased $(28,31)$ regimens. Previously, only one study by Yoshida et al. evaluated the predictive value of NLR in 44 TAS-102-treated patients with mCRC; it showed pretreatment NLR to be negatively significantly associated with PFS in multivariate analysis (32). Considering these consistent results, the NLR may serve as a versatile prognostic marker in patients with mCRC treated with 

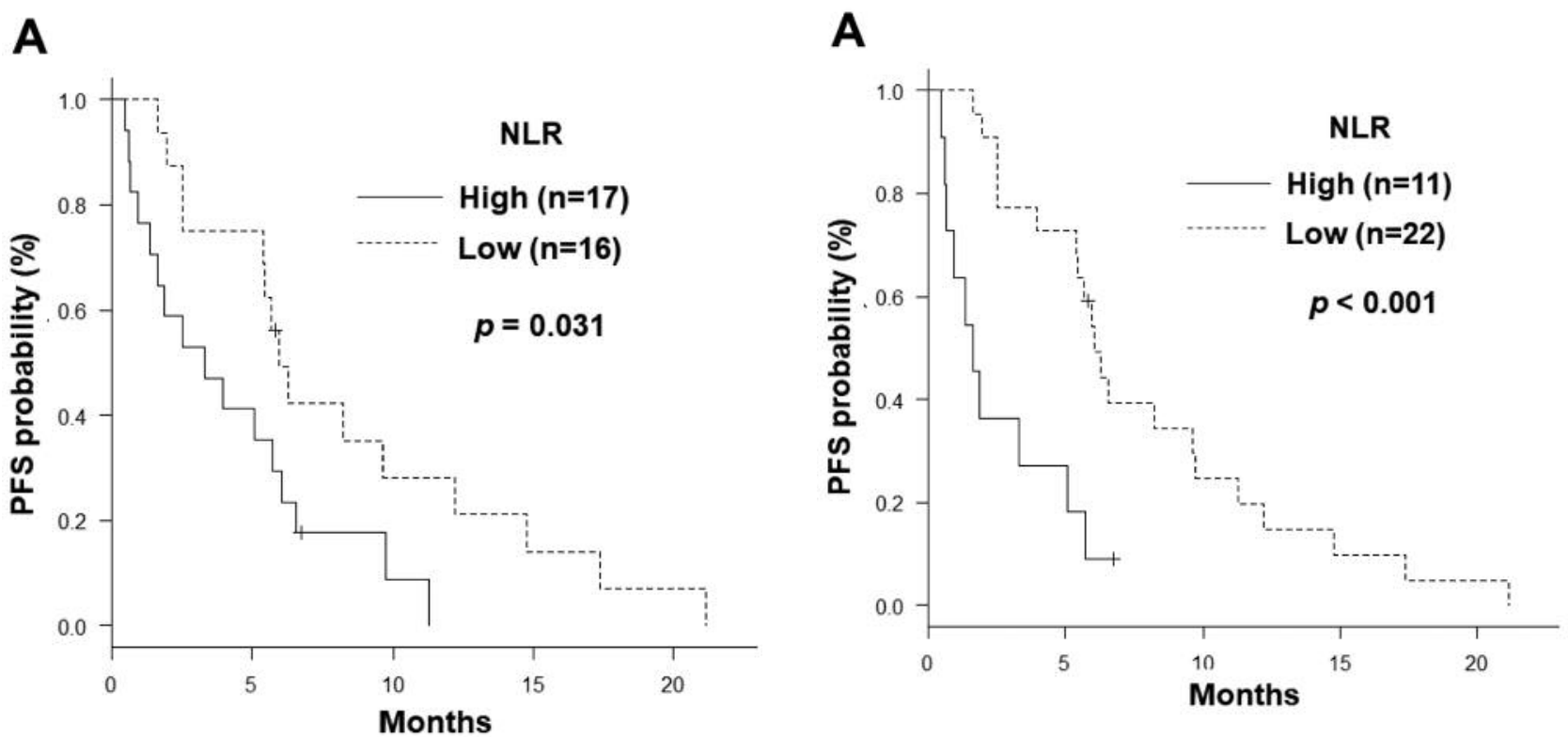

B

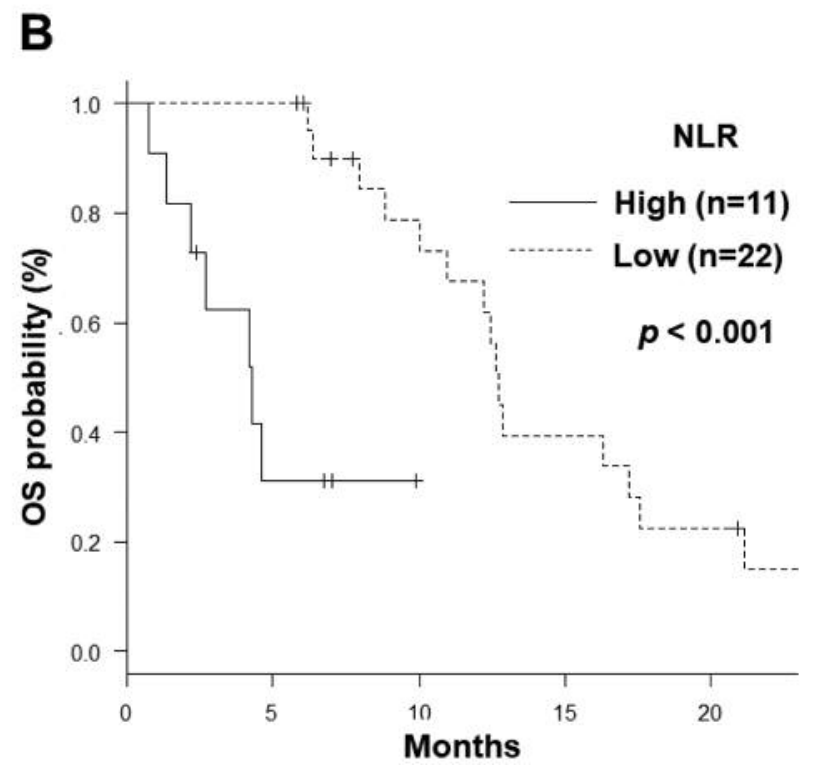

Figure 1. Kaplan-Meier curves showing progression-free (PFS) (A) and overall $(O S)(B)$ survival according to neutrophil-to-lymphocyte ratio (NLR) using the median value of 3.14 as cut-off.

chemotherapy regardless of targeted drugs. Additionally, the NLR is a convenient and cost-effective biomarker in clinical settings.

Although the NLR is increasingly considered to be a robust predictive biomarker based on abundant previous positive studies, the heterogenous cut-off values in each study have slowed the application of those ratios in clinical settings. A recent meta-analysis by Malietzis et al. evaluating

Figure 2. Kaplan-Meier curves showing progression-free (PFS) (A) and overall $(O S)(B)$ survival according to neutrophil-to-lymphocyte ratio (NLR) using a value of 5 as cut-off.

the predictive value of the NLR for oncological outcomes in patients with CRC also noted the heterogeneity as a critical limitation and suggested that the cut-off value should be $>3$ (33). Kubo et al. showed the predictive efficacy of the median value as a cut-off in patients who underwent curative surgery for CRC (34). Studies by Chua et al. (35) and Kishi et al. (27) showed the efficacy of 5 as the NLR cut-off in patients with $\mathrm{mCRC}$ treated with systemic chemotherapy. In 
Table II. Progression-free and overall survival according to predictive factors.

\begin{tabular}{|c|c|c|c|c|c|}
\hline Variable & & $\begin{array}{c}\text { Median PFS }(95 \% \mathrm{CI}), \\
\text { months }\end{array}$ & $p$-Value & $\begin{array}{c}\text { Median OS }(95 \% \mathrm{CI}) \\
\text { months }\end{array}$ & $p$-Value \\
\hline \multirow[t]{2}{*}{ Age } & $<75$ Years $(\mathrm{n}=25)$ & $5.45(1.9-8.2)$ & 0.362 & $12.45(6.4-17.6)$ & 0.282 \\
\hline & $\geq 75$ Years $(\mathrm{n}=8)$ & 5.37 (0.46-NA) & & $12.2(4.3-\mathrm{NA})$ & \\
\hline \multirow[t]{2}{*}{ Gender } & Male $(n=20)$ & $5.86(1.6-8.2)$ & 0.377 & $12.45(8.8-17.6)$ & 0.417 \\
\hline & Female $(n=13)$ & $3.97(1.8-6.3)$ & & $12.2(4.2-12.7)$ & \\
\hline \multirow[t]{2}{*}{ ECOG PS } & $0,1(n=28)$ & $5.75(2.5-8.2)$ & 0.007 & $12.45(8.8-16.3)$ & $<0.001$ \\
\hline & $\geq 2(n=5)$ & $1.74(1.3-\mathrm{NA})$ & & $2.69(1.3-\mathrm{NA})$ & \\
\hline \multirow[t]{2}{*}{ Primary site } & Right-sided ( $\mathrm{n}=8)$ & $4.21(1.3-9.7)$ & 0.839 & $12.45(1.3-12.7)$ & 0.708 \\
\hline & Left-sided $(n=25)$ & $5.45(2.0-6.6)$ & & $12.22(6.2-17.2)$ & \\
\hline \multirow[t]{2}{*}{ KRAS status } & Wild $(\mathrm{n}=17)$ & $5.45(1.3-6.0)$ & 0.626 & $7.98(4.3-\mathrm{NA})$ & 0.906 \\
\hline & Mutant $(\mathrm{n}=13)$ & $3.97(2.5-9.7)$ & & $12.45(4.6-17.2)$ & \\
\hline \multirow[t]{2}{*}{ Metastasis } & Synchronous $(\mathrm{n}=20)$ & $3.63(1.3-6.0)$ & 0.539 & $10.02(4.3-17.2)$ & 0.14 \\
\hline & Metachronous $(\mathrm{n}=13)$ & $6.05(2.5-9.7)$ & & $12.65(8.0-\mathrm{NA})$ & \\
\hline \multirow[t]{2}{*}{ Number of metastatic organs, $\mathrm{n}(\%)$} & $1(\mathrm{n}=13)$ & $8.25(2.5-11.3)$ & 0.070 & $12.85(8.0-\mathrm{NA})$ & 0.098 \\
\hline & $\geq 2(n=20)$ & $3.63(1.3-6.0)$ & & $8.83(4.2-12.5)$ & \\
\hline \multirow[t]{2}{*}{ Treatment line of TAS- 102} & $\leq 3(n=17)$ & $5.98(2.5-12.2)$ & 0.003 & $12.98(8.0-21.2)$ & 0.188 \\
\hline & $\geq 4(n=16)$ & $2.97(0.9-6.0)$ & & $10.94(4.3-16.3)$ & \\
\hline \multirow{2}{*}{ Time from diagnosis to TAS-102 (months)* } & $<23.9(\mathrm{n}=17)$ & $5.68(1.6-8.2)$ & 0.322 & $12.65(8.0-21.2)$ & 0.207 \\
\hline & $\geq 23.9(\mathrm{n}=16)$ & $5.43(1.8-6.6)$ & & $10.94(4.6-16.3)$ & \\
\hline \multirow[t]{2}{*}{ Reduced dose of initial TAS- 102} & Yes $(n=11)$ & $5.75(1.64-\mathrm{NA})$ & 0.701 & $12.22(6.2-16.3)$ & 0.787 \\
\hline & No $(n=22)$ & $4.70(1.8-8.2)$ & & $10.45(4.2-\mathrm{NA})$ & \\
\hline \multirow[t]{2}{*}{ Regorafenib treatment } & Yes $(n=6)$ & $6.11(0.62-\mathrm{NA})$ & 0.841 & $10.84(8.0-17.2)$ & 0.833 \\
\hline & No $(n=27)$ & $5.45(2.5-6.3)$ & & $10.45(0.7-\mathrm{NA})$ & \\
\hline \multirow[t]{2}{*}{ Combination with bevacizumab } & Yes $(n=6)$ & 4.17 (0.59-NA) & 0.759 & NA (2.2-NA) & 0.641 \\
\hline & No $(n=27)$ & $5.68(2.5-6.6)$ & & $12.5(8.0-16.3)$ & \\
\hline \multirow[t]{2}{*}{ Neutropenia $(\geq \mathrm{G} 2)$ in 1 month } & Yes $(n=6)$ & $5.26(1.6-\mathrm{NA})$ & 0.748 & $13.0(8.0-\mathrm{NA})$ & 0.813 \\
\hline & No $(n=27)$ & $5.68(2.0-8.2)$ & & $12.2(6.2-12.8)$ & \\
\hline \multirow[t]{2}{*}{ NLR (cut-off: 3.14 )* } & High $(n=17)$ & $3.29(0.9-6.0)$ & 0.0313 & 6.17 (2.7-NA) & 0.005 \\
\hline & Low $(n=16)$ & $5.98(2.5-12.2)$ & & $12.68(10.0-21.2)$ & \\
\hline \multirow[t]{2}{*}{ NLR (cut-off: 5) } & High $(n=11)$ & $1.64(0.6-5.1)$ & $<0.001$ & $4.30(1.3-\mathrm{NA})$ & $<0.001$ \\
\hline & Low $(n=22)$ & $6.05(4.0-9.7)$ & & $12.71(10.0-17.2)$ & \\
\hline \multirow[t]{2}{*}{ PLR (cut-off: 173.2)* } & High $(n=17)$ & $3.23(1.3-5.7)$ & 0.0183 & $7.98(4.3-12.5)$ & 0.003 \\
\hline & Low $(n=16)$ & $6.28(2.5-12.2)$ & & $16.33(8.8-21.2)$ & \\
\hline \multirow{2}{*}{ LMR (cut-off: 3.17$)^{*}$} & High $(n=17)$ & $6.27(2.5-9.8)$ & 0.0805 & $12.71(8.8-17.2)$ & 0.242 \\
\hline & Low $(n=16)$ & $2.89(1.3-5.7)$ & & 6.37 (2.7-NA) & \\
\hline
\end{tabular}

CI: Confidence interval; NA: not available; ECOG PS: Eastern Corporative Oncology Group performance status; NLR: neutrophil-to-lymphocyte ratio; PLR: platelet-to-lymphocyte ratio; LMR: lymphocyte-to-monocyte ratio; *Median value.

our study, we used both the median value of 3.14 , and 5 as cut-off values for NLR and compared them. The cut-off of 5 was superior and had considerable predictive potential for both PFS and OS in our cohort.

Another promising application of inflammatory-based scores as predictive biomarkers is longitudinal change before and after treatment. Formica et al. assessed changes in NLR before and after 1st-line FOLFIRI plus bevacizumab treatment and surprisingly showed that the degree of NLR change did not correlate with oncological outcomes and NLR increase led to significantly longer OS compared with NLR decrease, in patients with stable disease (29). These results were unexpected and suggested a confounding effect by chemotherapy-induced tumour shrinkage and latent factors that potentially influence the NLR. Several disease conditions are known to affect the NLR, including essential hypertension, acute coronary syndromes, renal and liver diseases, and some medications, such as antibiotics, antidiabetic and antihypertensive drugs (36-38).

Several studies of potential biomarkers have clarified their predictive power for TAS-102-treated mCRC. Yoshino et al. showed that high expression of TK1, which catalyses incorporation of FTD into DNA by phosphorylation, was associated with longer OS (9). Suenaga et al. reported that polymorphisms in genes involved in FTD and thymidine phosphorylase inhibitor pharmacokinetics may serve as predictive and prognostic markers in refractory mCRC treated with TAS-102 (8). However, clinicians cannot easily apply these biomarkers as a routine measurement. Kasi et al. demonstrated that neutropenia at 1 month after starting TAS- 
Table III. Efficacy and safety of TAS-102 treatment according to neutrophil-to-lymphocyte ratio (NLR) status (cut-off: 5).

\begin{tabular}{|c|c|c|c|c|}
\hline \multirow[b]{2}{*}{ Evaluation } & \multicolumn{4}{|c|}{ NLR, n (\%) } \\
\hline & All cases $(\mathrm{n}=33), \mathrm{n}(\%)$ & $<5(\mathrm{n}=22)$ & $\geq 5(\mathrm{n}=11)$ & $p$-Value \\
\hline \multicolumn{5}{|l|}{ Efficacy, n (\%) } \\
\hline Complete response & $0(0)$ & $0(0)$ & $0(0)$ & \\
\hline Partial response & $1(3.0)$ & $0(0)$ & $1(9.1)$ & \\
\hline Stable disease & $17(51.5)$ & $15(68.2)$ & $2(18.2)$ & \\
\hline Progressive disease & $14(4.2)$ & $7(31.8)$ & $7(63.6)$ & \\
\hline Not evaluated & $1(3.0)$ & $0(0)$ & $1(9.1)$ & \\
\hline ORR & $1(3.0)$ & $0(0)$ & $1(9.1)$ & 0.333 \\
\hline DCR & $18(54.5)$ & $15(68.2)$ & $3(27.3)$ & 0.061 \\
\hline \multicolumn{5}{|l|}{ Adverse event, n (\%) } \\
\hline Neutropenia & $14(42.4)$ & $12(54.5)$ & $2(18.2)$ & 0.067 \\
\hline Leukopenia & $9(27.2)$ & $6(27.3)$ & $3(27.3)$ & 1.00 \\
\hline Febrile neutropenia & $4(12.1)$ & $3(13.6)$ & $1(9.1)$ & 1.00 \\
\hline Anemia & $7(21.2)$ & $5(22.7)$ & $2(18.2)$ & 1.00 \\
\hline Thrombocytopenia & $2(6.1)$ & $2(9.1)$ & $0(0)$ & 0.542 \\
\hline Anorexia & $1(3.0)$ & $0(0)$ & $1(9.1)$ & 0.333 \\
\hline Nausea & $2(6.1)$ & $0(0)$ & $2(18.2)$ & 0.104 \\
\hline Fatigue & $1(3.0)$ & $0(0)$ & $1(9.1)$ & 0.333 \\
\hline
\end{tabular}

ORR: Overall response rate; DCR: disease control rate (ORR+stable disease). Adverse events grade 3 or more according to Common Terminology Criteria for Adverse Events, version 4.03 (14).

Table IV. Multivariate analysis using Cox proportional hazards model.

\begin{tabular}{|c|c|c|c|c|c|c|c|}
\hline \multirow[t]{2}{*}{ Variable } & \multirow[b]{2}{*}{ Group } & \multicolumn{3}{|c|}{ PFS } & \multicolumn{3}{|c|}{ OS } \\
\hline & & HR & $95 \% \mathrm{CI}$ & $p$-Value & HR & $95 \% \mathrm{CI}$ & $p$-Value \\
\hline ECOG PS & $\geq 2$ & 1.46 & $0.38-5.64$ & 0.5797 & 7.78 & $1.54-39.22$ & 0.0129 \\
\hline Number of organs with metastasis & $\geq 2$ & 2.22 & $1.00-4.95$ & 0.0499 & 2.06 & $0.83-5.14$ & 0.1203 \\
\hline Treatment line of TAS-102 & $\geq 4$ & 3.37 & $1.29-8.73$ & 0.0125 & - & - & - \\
\hline NLR (cut-off: 5) & High & 6.26 & $1.99-19.74$ & 0.0017 & 6.97 & $1.71-28.46$ & 0.0069 \\
\hline PLR (cut-off: 173.2) & High & 1.27 & $0.55-2.95$ & 0.5732 & 3.13 & $0.96-10.16$ & 0.0579 \\
\hline
\end{tabular}

CI: Confidence interval; ECOG PS: Eastern Corporative Oncology Group performance status; HR: hazard ratio; NLR: neutrophil-to-lymphocyte ratio; PLR: platelet-to-lymphocyte ratio; LMR: lymphocyte-to-monocyte ratio.

102 was associated with better prognosis (7), which may suggest that the dosage of TAS-102 should be increased to achieve better outcomes in patients who do not experience any neutropenia. However, our result was not consistent with this report. This may have been due to the differences in patient cohorts, characteristics, and tumour status. But patients with NLR $<5$ had a higher prevalence of neutropenia than those with NLR $\geq 5$ in the safety profile. This result indicates that the inflammation-induced increased neutrophil count of the NLR $\geq 5$ group had protected them from severe neutropenia. Taken together with the fact that the group with a low NLR had longer survival, neutropenia might be a surrogative prognostic marker.
The major limitations of our study are its retrospective nature, small sample size, and single-centre Japanese-based cohort. The predictive value of NLR was not compared with other reported biomarkers, such as TK1 and specific polymorphisms. In conclusion, we describe the predictive and prognostic value of pretreatment NLR in refractory mCRC patients with TAS-102 treatment. However, further high-quality studies with larger cohorts are required to confirm this finding.

\section{Author Contributions}

Study concept and design: Matsuda A. and Yamada T. Acquisition of data: Matsuda A. Matsumoto S. Sakurazawa N. Kawano Y. 
Shinozuka E. and Sekiguchi K. Analysis and interpretation of data: Matsuda A., Yamada T., and Matsumoto S. Drafting of the article: Matsuda A. Study supervision: Suzuki H. and Yoshida H.

\section{Acknowledgements}

The Authors thank Marla Brunker, from Edanz Group (www.edanzediting.com/ac), for editing a draft of this article.

\section{References}

1 Emura T, Suzuki N, Fujioka A, Ohshimo H and Fukushima M: Potentiation of the antitumor activity of alpha, alpha, alphatrifluorothymidine by the co-administration of an inhibitor of thymidine phosphorylase at a suitable molar ratio in vivo. Int $\mathbf{J}$ Oncol 27(2): 449-455, 2005. PMID: 16010427.

2 Temmink OH, Emura T, de Bruin M, Fukushima M and Peters GJ: Therapeutic potential of the dual-targeted Tas-102 formulation in the treatment of gastrointestinal malignancies. Cancer Sci 98(6): 779-789, 2007. DOI: 10.1111/j.1349-7006.2007.00477.x

3 Mayer RJ, Van Cutsem E, Falcone A, Yoshino T, Garcia-Carbonero R, Mizunuma N, Yamazaki K, Shimada Y, Tabernero J, Komatsu Y, Sobrero A, Boucher E, Peeters M, Tran B, Lenz HJ, Zaniboni A, Hochster H, Cleary JM, Prenen H, Benedetti F, Mizuguchi H, Makris L, Ito M, Ohtsu A and Group RS: Randomized trial of Tas102 for refractory metastatic colorectal cancer. N Engl J Med 372(20): 1909-1919, 2015. DOI: 10.1056/NEJMoa1414325

4 Xu J, Kim TW, Shen L, Sriuranpong V, Pan H, Xu R, Guo W, Han SW, Liu T, Park YS, Shi C, Bai Y, Bi F, Ahn JB, Qin S, Li Q, Wu C, Ma D, Lin D and Li J: Results of a randomized, double-blind, placebo-controlled, phase iii trial of trifluridine/tipiracil (Tas-102) monotherapy in Asian patients with previously treated metastatic colorectal cancer: The Terra study. J Clin Oncol 36(4): 350-358, 2018. DOI: 10.1200/JCO. 2017.74.3245

5 Yoshino T, Mizunuma N, Yamazaki K, Nishina T, Komatsu Y, Baba H, Tsuji A, Yamaguchi K, Muro K, Sugimoto N, Tsuji Y, Moriwaki T, Esaki T, Hamada C, Tanase T and Ohtsu A: Tas102 monotherapy for pretreated metastatic colorectal cancer: A double-blind, randomised, placebo-controlled phase 2 trial. Lancet Oncol 13(10): 993-1001, 2012. PMID: 22951287. DOI: 10.1016/S1470-2045(12)70345-5

6 Hamauchi S, Yamazaki K, Masuishi T, Kito Y, Komori A, Tsushima T, Narita Y, Todaka A, Ishihara M, Yokota T, Tanaka T, Machida N, Kadowaki S, Fukutomi A, Ura T, Onozawa Y, Ando M, Tajika M, Muro K, Yasui H, Mori K and Taniguchi H: Neutropenia as a predictive factor in metastatic colorectal cancer treated with Tas-102. Clin Colorectal Cancer 16(1): 51-57, 2017. PMID: 27522626. DOI: 10.1016/j.clcc.2016.07.005

7 Kasi PM, Kotani D, Cecchini M, Shitara K, Ohtsu A, Ramanathan RK, Hochster HS, Grothey A and Yoshino T: Chemotherapy induced neutropenia at 1-month mark is a predictor of overall survival in patients receiving Tas-102 for refractory metastatic colorectal cancer: A cohort study. BMC Cancer 16: 467, 2016. PMID: 4944251. DOI: 10.1186/s12885-016-2491-y

8 Suenaga M, Schirripa M, Cao S, Zhang W, Yang D, Dadduzio V, Salvatore L, Borelli B, Pietrantonio F, Ning Y, Okazaki S, Berger MD, Miyamoto Y, Gopez R Jr., Barzi A, Yamaguchi T, Loupakis F and Lenz HJ: Potential role of polymorphisms in the transporter genes ENT1 and MATE1/OCT2 in predicting Tas-
102 efficacy and toxicity in patients with refractory metastatic colorectal cancer. Eur J Cancer 86: 197-206, 2017. PMID: 28992563. DOI: 10.1016/j.ejca.2017.08.033

9 Yoshino T, Yamazaki K, Shinozaki E, Komatsu Y, Nishina T, Baba H, Tsuji A, Tsuji Y, Yamaguchi K, Sugimoto N, Denda T, Muro K, Takayama T, Esaki T, Hamamoto Y, Moriwaki T, Shimada Y, Goto M, Nakayama N, Fujii H, Tanase T and Ohtsu A: Relationship between thymidine kinase 1 expression and trifluridine/tipiracil therapy in refractory metastatic colorectal cancer: A pooled analysis of 2 randomized clinical trials. Clin Colorectal Cancer 17(4): e719-e732, 2018. PMID: 30172759. DOI: $10.1016 /$ j.clcc.2018.07.009

10 Chen ZY, Raghav K, Lieu CH, Jiang ZQ, Eng C, Vauthey JN, Chang GJ, Qiao W, Morris J, Hong D, Hoff P, Tran H, Menter DG, Heymach J, Overman M and Kopetz S: Cytokine profile and prognostic significance of high neutrophil-lymphocyte ratio in colorectal cancer. Br J Cancer 112(6): 1088-1097, 2015. PMID: 4366901. DOI: $10.1038 / \mathrm{bjc} .2015 .61$

11 Coussens LM and Werb Z: Inflammation and cancer. Nature 420(6917): 860-867, 2002. PMID: 2803035. DOI: 10.1038/ nature 01322

12 Dell'Aquila E, Cremolini C, Zeppola T, Lonardi S, Bergamo F, Masi G, Stellato M, Marmorino F, Schirripa M, Urbano F, Ronzoni M, Tomasello G, Zaniboni A, Racca P, Buonadonna A, Allegrini G, Fea E, Di Donato S, Chiara S, Tonini G, Tomcikova D, Boni L, Falcone A and Santini D: Prognostic and predictive role of neutrophil/ lymphocytes ratio in metastatic colorectal cancer: A retrospective analysis of the Tribe study by GONO. Ann Oncol 29(4): 924-930, 2018. PMID: 29324972. DOI: 10.1093/annonc/mdy004

13 Song Y, Yang Y, Gao P, Chen X, Yu D, Xu Y, Zhao J and Wang $\mathrm{Z}$ : The preoperative neutrophil to lymphocyte ratio is a superior indicator of prognosis compared with other inflammatory biomarkers in resectable colorectal cancer. BMC Cancer 17(1): 744, 2017. PMID: 5681757. DOI: 10.1186/s12885-017-3752-0

14 Department of Health and Human Services National Institute of Health: Common Terminology Criteria for Adverse Events (CTCAE)V4. 03 2010. Available at: Http://evs.Nci.Nih.Gov/ftp1/ ctcae/ctcae_4.03_2010-06-14_quickreference_5x7.Pdf (Last accessed December 21, 2015).

15 Eisenhauer EA, Therasse P, Bogaerts J, Schwartz LH, Sargent D, Ford R, Dancey J, Arbuck S, Gwyther S, Mooney M, Rubinstein L, Shankar L, Dodd L, Kaplan R, Lacombe D and Verweij J: New Response Evaluation Criteria in Solid Tumours: Revised RECIST guideline (version 1.1). Eur J Cancer 45(2): 228-247, 2009. PMID: 19097774. DOI: 10.1016/j.ejca.2008. 10.026

16 Lee DY, Hong SW, Chang YG, Lee WY and Lee B: Clinical significance of preoperative inflammatory parameters in gastric cancer patients. J Gastric Cancer 13(2): 111-116, 2013. PMID: 3705131. DOI: $10.5230 /$ jgc.2013.13.2.111

17 Nagasaki T, Akiyoshi T, Fujimoto Y, Konishi T, Nagayama S, Fukunaga Y and Ueno M: Prognostic impact of neutrophil-tolymphocyte ratio in patients with advanced low rectal cancer treated with preoperative chemoradiotherapy. Dig Surg 32(6): 496-503, 2015. PMID: 26544755. DOI: 10.1159/000441396

18 Pichler M, Hutterer GC, Stoeckigt C, Chromecki TF, Stojakovic T, Golbeck S, Eberhard K, Gerger A, Mannweiler S, Pummer K and Zigeuner R: Validation of the pre-treatment neutrophillymphocyte ratio as a prognostic factor in a large European cohort of renal cell carcinoma patients. Br J Cancer 108(4): 901907, 2013. PMID: 3590665. DOI: 10.1038/bjc.2013.28 
19 Stotz M, Gerger A, Eisner F, Szkandera J, Loibner H, Ress AL, Kornprat P, AlZoughbi W, Seggewies FS, Lackner C, Stojakovic T, Samonigg H, Hoefler G and Pichler M: Increased neutrophillymphocyte ratio is a poor prognostic factor in patients with primary operable and inoperable pancreatic cancer. Br J Cancer 109(2): 416421, 2013. PMID: 3721392. DOI: 10.1038/bjc. 2013.332

20 Yodying H, Matsuda A, Miyashita M, Matsumoto S, Sakurazawa $N$, Yamada $M$ and Uchida E: Prognostic significance of neutrophil-to-lymphocyte ratio and platelet-to-lymphocyte ratio in oncologic outcomes of esophageal cancer: A systematic review and meta-analysis. Ann Surg Oncol 23(2): 646-654, 2016. PMID: 26416715. DOI: 10.1245/s10434-015-4869-5

21 Grivennikov SI, Greten FR and Karin M: Immunity, inflammation, and cancer. Cell 140(6): 883-899, 2010. PMID: 2866629. DOI: $10.1016 /$ j.cell.2010.01.025

22 Balkwill $\mathrm{F}$ and Mantovani A: Inflammation and cancer: Back to Virchow? Lancet 357(9255): 539-545, 2001. DOI: 10.1016/ S0140-6736(00)04046-0

23 Evans C, Dalgleish AG and Kumar D: Review article: Immune suppression and colorectal cancer. Aliment Pharmacol Ther 24(8): 1163-1177, 2006. DOI: 10.1111/j.1365-2036.2006. 03075.x

24 McMillan DC, Fyffe GD, Wotherspoon HA, Cooke TG and McArdle CS: Prospective study of circulating T-lymphocyte subpopulations and disease progression in colorectal cancer. Dis Colon Rectum 40(9): 1068-1071, 1997. PMID: 9293937.

25 Bambace NM and Holmes CE: The platelet contribution to cancer progression. J Thromb Haemost 9(2): 237-249, 2011. PMID: 21040448. DOI: 10.1111/j.1538-7836.2010.04131.x

26 Dirican A, Varol U, Kucukzeybek Y, Alacacioglu A, Erten C, Somali I, Can A, Demir L, Bayoglu IV, Akyol M, Yildiz Y, Koyuncu B, Coban E and Tarhan MO: Treatment of metastatic colorectal cancer with or without bevacizumab: Can the neutrophil/lymphocyte ratio predict the efficiency of bevacizumab? Asian Pac J Cancer Prev 15(12): 4781-4786, 2014. PMID: 24998541. DOI: 10.7314/apjcp.2014.15.12.4781

27 Kishi Y, Kopetz S, Chun YS, Palavecino M, Abdalla EK and Vauthey JN: Blood neutrophil-to-lymphocyte ratio predicts survival in patients with colorectal liver metastases treated with systemic chemotherapy. Ann Surg Oncol 16(3): 614-622, 2009. PMID: 19130139. DOI: 10.1245/s10434-008-0267-6

28 Yang J, Guo X, Wang M, Ma X, Ye X and Lin P: Pre-treatment inflammatory indexes as predictors of survival and cetuximab efficacy in metastatic colorectal cancer patients with wild-type RAS. Sci Rep 7(1): 17166, 2017. PMID: 5719445. DOI: 10.1038/s41598-017-17130-6

29 Formica V, Lucchetti J, Cunningham D, Smyth EC, Ferroni P, Nardecchia A, Tesauro M, Cereda V, Guadagni F and Roselli M: Systemic inflammation, as measured by the neutrophil/ lymphocyte ratio, may have differential prognostic impact before and during treatment with fluorouracil, irinotecan and bevacizumab in metastatic colorectal cancer patients. Med Oncol 31(9): 166, 2014. PMID: 25148896. DOI: 10.1007/ s12032-0140166-6

30 Kaneko M, Nozawa H, Sasaki K, Hongo K, Hiyoshi M, Tada N, Murono K, Nirei T, Kawai K, Sunami E, Tsuno NH and Kitayama J: Elevated neutrophil to lymphocyte ratio predicts poor prognosis in advanced colorectal cancer patients receiving oxaliplatin-based chemotherapy. Oncology 82(5): 261-268, 2012. PMID: 22538399. DOI: $10.1159 / 000337228$
31 Sunakawa Y, Yang D, Cao S, Zhang W, Moran M, Astrow SH, Hsiang J, Stephens C, Tsuji A, Takahashi T, Tanioka H, Negoro Y, Takagane A, Tani S, Yamaguchi T, Eto T, Fujii M, Ichikawa $\mathrm{W}$ and Lenz HJ: Immune-related genes to dominate neutrophillymphocyte ratio (NLR) associated with survival of cetuximab treatment in metastatic colorectal cancer. Clin Colorectal Cancer 17(4): e741-e749, 2018. PMID: 6249067. DOI: 10.1016/ j.clcc.2018.08.002

32 Yoshida Y, Sakamoto R, Kajitani R, Munechika T, Matsumoto Y, Komono A, Aisu N, Daibo K, Kiyomi F and Hasegawa S: Biweekly administration of Tas-102 for neutropenia prevention in patients with colorectal cancer. Anticancer Res 38(7): 43674373, 2018. PMID: 29970575. DOI: 10.21873/anticanres.12738

33 Malietzis G, Giacometti M, Kennedy RH, Athanasiou T, Aziz O and Jenkins JT: The emerging role of neutrophil to lymphocyte ratio in determining colorectal cancer treatment outcomes: A systematic review and meta-analysis. Ann Surg Oncol 21(12): 3938-3946, 2014. PMID: 24866438. DOI: 10.1245/s10434-0143815-2

34 Kubo T, Ono S, Ueno H, Shinto E, Yamamoto J and Hase K: Impact of the perioperative neutrophil-to-lymphocyte ratio on the long-term survival following an elective resection of colorectal carcinoma. Int J Colorectal Dis 29(9): 1091-1099, 2014. PMID: 25048875. DOI: 10.1007/s00384-014-1964-1

35 Chua W, Charles KA, Baracos VE and Clarke SJ: Neutrophil/ lymphocyte ratio predicts chemotherapy outcomes in patients with advanced colorectal cancer. Br J Cancer 104(8): 1288-1295, 2011. PMID: 3078587. DOI: $10.1038 / \mathrm{bjc} .2011 .100$

36 Miyamoto T, Carrero JJ and Stenvinkel P: Inflammation as a risk factor and target for therapy in chronic kidney disease. Curr Opin Nephrol Hypertens 20(6): 662-668, 2011. PMID: 21825982. DOI: $10.1097 / \mathrm{MNH} .0 \mathrm{~b} 013 \mathrm{e} 32834 \mathrm{ad} 504$

37 Pitsavos C, Tampourlou M, Panagiotakos DB, Skoumas Y, Chrysohoou C, Nomikos $\mathrm{T}$ and Stefanadis C: Association between low-grade systemic inflammation and type 2 diabetes mellitus among men and women from the Attica study. Rev Diabet Stud 4(2): 98-104, 2007. PMID: 2036265. DOI: 10.1900/ RDS.2007.4.98

38 Sagawa M, Yoshimatsu K, Yokomizo H, Yano Y, Okayama S, Usui T, Yamaguchi K, Shiozawa S, Shimakawa T, Katsube T, Kato $\mathrm{H}$ and Naritaka Y: Worse preoperative status based on inflammation and host immunity is a risk factor for surgical site infections in colorectal cancer surgery. J Nippon Med Sch 84(5): 224-230, 2017. PMID: 29142183. DOI: $10.1272 /$ jnms .84 .224 